\title{
Commentary: Ruptured double-chambered left ventricle in association with coronary artery disease
}

\author{
Koh Takeuchi, MD, PhD
}

\author{
From the Department of Cardiovascular Surgery, Hanyu General Hospital, Hanyu, Saitama, Japan. \\ Disclosures: Author has nothing to disclose with regard to commercial support. \\ Received for publication July 14, 2019; accepted for publication July 17, 2019; available ahead of print Sept 5, \\ 2019. \\ Address for reprints: Koh Takeuchi, MD, PhD, Department of Cardiovascular Surgery, Hanyu General Hospital, \\ 446 Shimoiwase, Hanyu Saitama, Japan 348-8505 (E-mail: koutakeuchi-circ@umin.ac.jp). \\ J Thorac Cardiovasc Surg 2020;159:e197-8 \\ $0022-5223 / \$ 36.00$ \\ Copyright (C) 2019 by The American Association for Thoracic Surgery \\ https://doi.org/10.1016/j.jtcvs.2019.07.028
}

The etiology of the double-chambered left ventricle (DCLV) is little known, but the anomaly is thought to be congenital and a feature of nonprogressive diseases, ${ }^{1}$ although some patients with DCLV have died during the follow-up period due to associated anomalies such as cardiomyopathy. ${ }^{2}$ DCLV is characterized by the division of the left ventricular (LV) chamber into 2 chambers by abnormal muscular tissue. Double-chambered right ventricle, in which the outflow tract of the right ventricle is separated into a proximal high-pressure chamber and a distal low-pressure chamber, is more common than DCLV. It can be caused by the presence of hypertrophied anomalous muscle such as trabecular bands, or an aberrant moderator band, which typically results in progressive obstruction of the right ventricular outflow tract.

The DCLV is clearly different from ventricular aneurysm, which lacks complete layering of the ventricular wall, ${ }^{3}$ whereas the DCLV exhibits complete layering of the ventricle and contractile motion during systole. Since it is extremely rare, no definite data regarding the prognosis, outcomes, and potential complications, such as risk of embolism or rupture of DCLV, are available. Treatment, if any, is usually guided by the presence of other associated abnormalities. Surgical excision of the accessory chamber with interposition patch reconstruction and cardiac transplant are reported. ${ }^{4}$ Computed tomography ${ }^{5}$ would be a gold standard in terms of detecting accessory septum and a DCLV. Magnetic resonance imaging ${ }^{4}$ can be useful with regard to detecting scarring, fibrosis, or fibroelastosis, as well as a synchronized ventricular motion, which makes it distinct from an LV aneurysm.

Park and colleagues ${ }^{6}$ reported the successful repair of a ruptured LV aneurysm in a patient with DCLV. They supposed that a pre-existing structural defect in the DCLV might have been aggravated by myocardial infarction, which changed to a small outpouching and led to a rupture of the LV. Another previous report ${ }^{7}$ suggested the potential risk of rupture of the accessory chamber of the DCLV due to

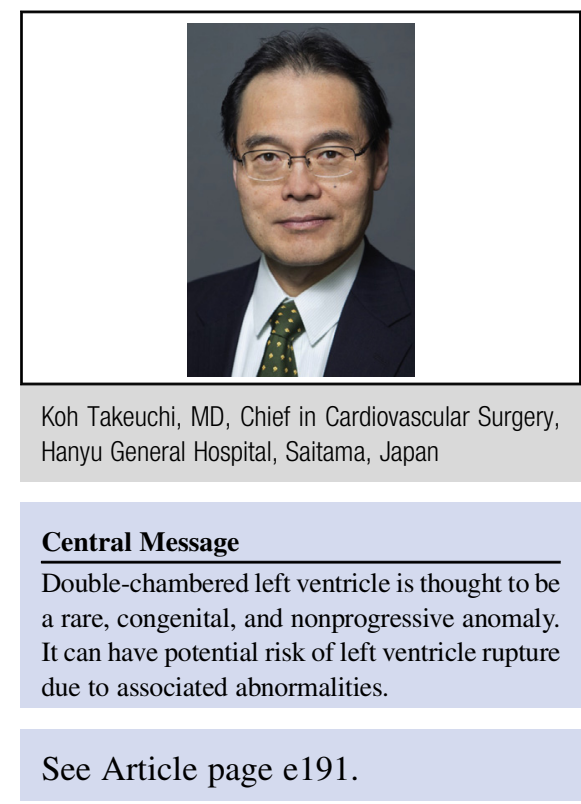

a structurally thin wall. Although this anomaly is thought to be nonprogressive and less risk to the patient, associated abnormalities may cause structural disruption and lead to a life-threatening condition, as seen in their report. The patient didn't display any risk factors in terms of coronary artery disease or any other significant coronary lesion. It is unclear how it is closely related to acute coronary artery dissection. We need to take this into consideration during the follow-up period of patients with DCLV.

This is an interesting report that provides us an information about the potential risk of rupture of the DCLV. I congratulate the authors' successful surgical treatment of patient with ruptured DCLV.

\section{References}

1. Zhang WM, Chang DQ, Huang JJ, Maimaitiaili A, Ermek T, Yisireyili M, et al Double-chambered left ventricle: a rare case in a child. Echocardiography. 2019;36:192-5

2. Gerlis LM, Partridge JB, Fiddler GI, Williams G, Scott O. Two chambered left ventricle. Three new varieties. Br Heart J. 1981;46:278-84.

3. Award SM, Patel AS, Polimenakos A, Braun R, Abdulla RI. Left ventricular accessory chamber: a case report and review of the literature. Pediatr Cardiol. 2009;30: 1022-5.

4. Kilner PJ, Geva T, Kaemmerer H, Trindade PT, Schwitter J, Webb GD. Recommendations for cardiovascular magnetic resonance in adults with congenital heart disease from the respective working groups of the European Society of Cardiology. Eur Heart J. 2010;31:794-805.

5. Breithardt OA, Ropers D, Seeliger T, Schmid A, von Erffa J, Garlichs C, et al. A heart within the heart: double-chambered left ventricle. Eur J Echocardiogr. 2008; 9:739-41. 
6. Park WK, Kim DH, Kwak YT, Cho SH. Double-chambered left ventricle discovered in patient with ruptured left ventricular aneurysm after myocardial infarction. J Thorac Cardiovasc Surg. 2020;159:e191-4.
7. Masci PG, Pucci A, Fontanive P, Coceani M, Marraccini P, Lombardi M. Double chambered left ventricle in an asymptomatic adult patient. Eur Heart J Cardiovasc Imaging. 2012;13:E1-3. 